\title{
PASS-THROUGH FREIGHT MODELING AT THE STATEWIDE AND METROPOLITAN LEVEL
}

\author{
Michael D. Anderson', Mallikarjuna Kenchappagoudra ${ }^{2}$, Mary Catherine Dondapati ${ }^{3}$, \\ Gregory A. Harris ${ }^{4}$ \\ ${ }_{1,2,3}$ Civil and Environmental Engineering, The University of Alabama in Huntsville, Huntsville, AL 35899 \\ ${ }^{4}$ Logistics and Transportation, The University of Alabama in Huntsville, Huntsville, AL 35899
}

Received 8 May 2013; accepted 20 January 2014

\begin{abstract}
The ability to determine the volumes of freight (specifically trucks) passing through a state or metropolitan area is difficult to determine/forecast because transportation professionals have no direct survey mechanism to collect this data. This paper documents various procedures developed to utilize the Freight Analysis Framework Version 2 Database to determine the number of trucks passing through the entire state and an urban area in Alabama. The procedures developed in this research focus on national level pass through data, trips from one state to another that pass through a state only because of that state's location; pass through from a port of entry to the country where an urbanized area is located on a major corridor; and statewide level through trip data, trips from one part of a state to another that pass through an urbanized area because of its geographic location. The need for, and application of, the pass through freight forecasting is evident in the transportation planning models each metropolitan area and state are expected to develop and maintain for evaluating transportation projects. The ability to accurately forecast the pass through freight movements will benefit transportation planners by identifying freight volumes that must be accommodated by existing and proposed infrastructure, but for which the state or metropolitan area has no direct method to survey.
\end{abstract}

Keywords: freight modeling, transport modeling.

\section{Introduction}

The efficient and effective movement of freight is a critical component in the transformation and growth of the economy. The ability to predict freight transportation requirements is vital to planning the necessary infrastructure improvements that can ensure congestion along a state's highways does not lead to a reduction in economic development (UAH Office for Economic Development, 2005). Transportation models must include predictions of freight movements. The freight predictions include those internal to the study area, those that either are attracted to or originate from the study area and those external to the study area that are a result of the freight passing through (E-E trips). The trips that have either the origination (I-E trips) or destination (E-I trips) in the study area are easier to model because the industries or retail outlets responsible for the freight activity are located in the study area and can be surveyed to determine the volume of freight flows produced or attracted. Qian et al. (2012) developed a methodology to predict E-E, E-I and I-E passenger trips crossing a small and medium sized study area (Qian et al., 2012). The

\footnotetext{
${ }^{1}$ Corresponding author: andersmd@uah.edu
} 
freight trips that are external to the study are more difficult to model because the planner is not able to survey industries or retail outlets that produce or attract the freight. In the absence of the survey data NCHRP Report 365 represents an indirect method to estimate external trips in small communities with population less than 50,000 (Martin and McGuckin, 1998.). The difficulty with obtaining this critical data has been identified in research performed on other statewide models and guides that indicate a trip exchange table for externalexternal freight transportation is necessary, but no clear guidance is provided to develop the trip table (Horowitz, 2006; Cohen and Horowitz, 2008).

This paper focuses on the development of tools and procedures to utilize the Federal Highway Administrations (FHWA) Freight Analysis Framework, Version 2 (FAF2) database to forecast and model pass-through freight. The tools and procedures will be designed and built using national, statewide and local levels for analysis. This paper presents work performed to determine a new methodology to develop pass-through freight volumes for the entire state using a national level approach. The paper then focuses on the development of a statewide freight flow model for Alabama that can then bring the passthrough to the local level. Finally, this paper concludes with an analysis of pass-through freight at the metropolitan level, referred as Metropolitan Planning Organizations (MPOs). The methodology presented in this paper is a new approach to determining freight movements for roadways.

\section{FAF2 Data}

The accuracy of any modeling activity is based on the quality of data entered into the process. For freight applications, the best data that is currently available is the Federal Highway Administration's Freight Analysis Framework (FAF) database.

The second generation of the Freight Analysis Framework (FAF) known as FAF2 is a continuation of the original Freight Analysis Framework developed by the U.S. Department of Transportation, Federal Highway Administration (FHWA) (Harris and Anderson, 2008). Whereas the original FAF provided the public with generalized freight movement and highway congestion maps without disclosing the underlying data, FAF2 provides a commodity flow origindestination (O-D) and freight movement data on all highways within the FAF2 highway network. The FAF2 Commodity OriginDestination Database estimates tonnage and value of goods shipped by type of commodity and mode of transportation for 114 FAF2 zones, 7 international trading regions and 17 additional international gateways (FHWA $3,2006)$. The 2002 estimate is primarily derived from the Commodity Flow Survey (CFS) with some of the data voids in the CFS filled in by analysis of the Economic Census and other data sources. Forecasts are included for 2010 to 2035 in 5-year increments (FHWA 1, 2006). The data are available in Microsoft Access format and contain values in millions of dollars of value and thousands of short tons. A listing of commodities can be obtained (FHWA $2,2006)$ as well as geographical zone distribution (FHWA 3, 2006) and modes of travel (FHWA 2, 2006).

\section{Statewide Pass-Through}

The initial level of analysis undertaken in this work was to focus on the statewide level through the analysis of national pass

\section{jitte 2}


through freight. This freight was essentially comprised of those movements where Alabama was in the unfortunate position of being between origin-destination locations, but the freight activity in no way was primary to Alabama. An example of this freight passthrough would be freight traveling from South Carolina to Louisiana. Alabama in not primary to this freight movement, however, this freight movement would impact travelers in Alabama and consume roadway capacity within the state and MPOs. NCHRP Report 606 shows methodology to forecast multimodal freight trips from external station survey data. The trip generation rates for the external truck trips (E-I and I-E) and the pass-through trips (E-E) are also incorporated in the models.

The methodology to develop the externalexternal table from the FAF2 database is comprised of the following steps:

1. Develop a national travel demand network that includes all 114 zones defined by the FAF2 database.

2. Perform a select link analysis technique in a commonly used travel demand model to determine which origin/ destination pairs use roadways in the desired study area or state.

3. Extract the relevant data from the FAF2 database based on the O/D pairs obtained in step 2, either in dollar value of shipment or tons shipped.

4. Use the O/D pairs and data in a travel forecasting model to determine external-external trips.

The steps listed above are explained in further detail in the following sections.

\subsection{Create a National Network}

The national network is designed to provide a basis for using a travel demand software package to determine the external-external traffic flows. The creation of the network involves the development of zones and roadway infrastructure similar to what would be performed to develop a traditional urban planning model. Any travel demand software can be used to create the network and run the model.

The FAF2 data structure defining the 114 zones (FHWA 3, 2006) of freight origin and destination should serve as the base zone structure for the travel demand model network. To improve the analysis, a geographic file that contains the 114 regions can be downloaded from the FAF2 website (FHWA 1, 2006).This geographic data is intended to be the starting point for the analysis.

The roadway network developed serves as the connection between the zones. The travel demand network should include roadway distances, travel speeds and capacities. To assist in the analysis, a geographic file containing transportation infrastructure is available for download from the FAF2 website (FHWA 1, 2006).

\subsection{Perform Flow Analysis}

After the national infrastructure network has been developed, a flow analysis is performed to determine the travel patterns and identify which $\mathrm{O} / \mathrm{D}$ pairs utilize the roadways in the area or state of interest. This can be accomplished through various methods based upon the travel demand model being employed for the study. Traffic must be assigned from each zone independently and 
the path to the other 113 destination zones can be determined. The $\mathrm{O} / \mathrm{D}$ pairs that use roadways in the area or state of interest can then be identified. The O/D pairs that use the roadways in the study area or state can then be used in the analysis.

\subsection{Run Computer Program to Extract Data}

After the $\mathrm{O} / \mathrm{D}$ pairs that traverse the area or state of interest are determined in task 2 , the FAF2 database must be reduced to contain only data for the O/D pairs of interest. To assist this step, researchers at the University of Alabama in Huntsville, Office for Freight, Logistics and Transportation developed a computer program in $\mathrm{C}++$ that allows the user to input the relevant $\mathrm{O} / \mathrm{D}$ pairs in a text file. The program generates an externalexternal table for the area or state in either the value of shipment in dollars or tons shipped.

\subsection{Assign Data to National Network}

Once the external-external data is developed, the user must assign the data to the national network. The assignment should be performed using the travel demand model and the user defined assignment procedure. This will allow for the analysis of external-external value of shipment or tons shipped to be assigned to the travel demand network. The assignment must be converted to the number of vehicles to be used for modeling purpose. The conversion factors for turning value of shipments or tons shipped into an accurate number of vehicles for each commodity and mode are critical to the freight planning process, and are of great concern, but is the subject for a future research paper.

The development of the external-external data and assignment can be accomplished by performing the steps of the methodology presented above. Planners can use the process described to create the data for the base level of freight traffic on the transportation facilities in their area of concern, whether local or statewide.

\section{Statewide Alabama Pass-Through}

To demonstrate the application of the methodology, an analysis of the externalexternal (pass through) data was performed for the state of Alabama. Included in the case study description is increased detail and documentation of specific steps when using TRANPLAN, which is the travel demand model used in Alabama.

The first task was the development of the national network. The FAF2 website provides a starting point by providing a national infrastructure. The infrastructure, in ArcGIS format, was downloaded and is shown in Fig. 1. From this data, the Interstate routes were highlighted and used to create a national network to connect the zones defined in the FAF2 database (Fig. 2). The national network was developed using CUBE-TRANPLAN, the travel demand model currently being used in Alabama for transportation forecasting. The national network was comprised of 114 zones (as defined by the FAF2 regions), nodes to reflect intersections and links to serve as roadways. The roadway was manually developed and the nodes and links were drawn using a "heads-up" digitizing technique with the ArcGIS file serving as an image layer to ensure the roadways were spatially accurate. Attributes were applied to the network such as roadway distances, speed limits and capacities. However, as the use of the network was to determine shortest path between zones, flows were not constrained by capacity.

\section{ijtte 4}



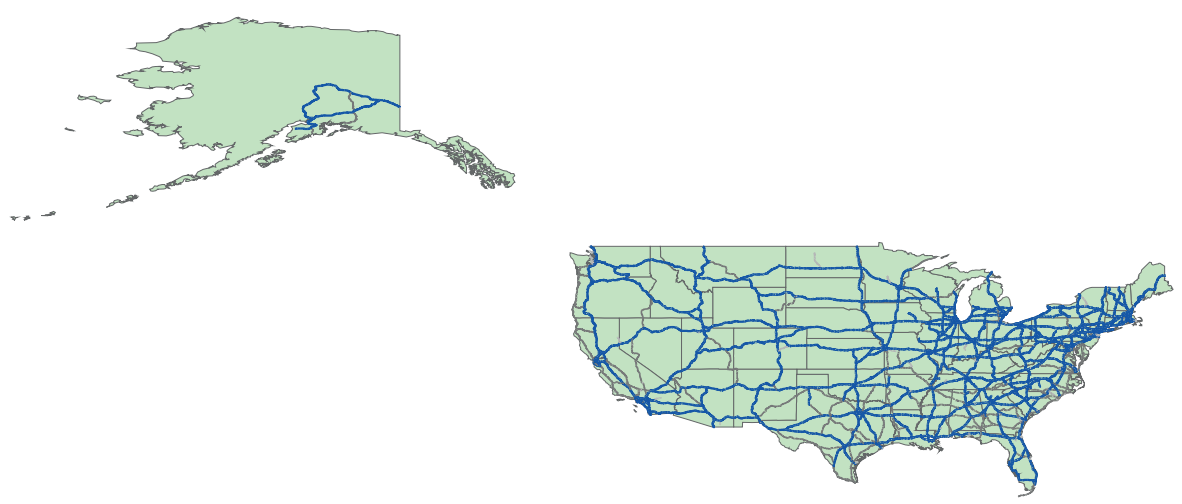

Fig. 1.

Roadway Infrastructure from FAF2

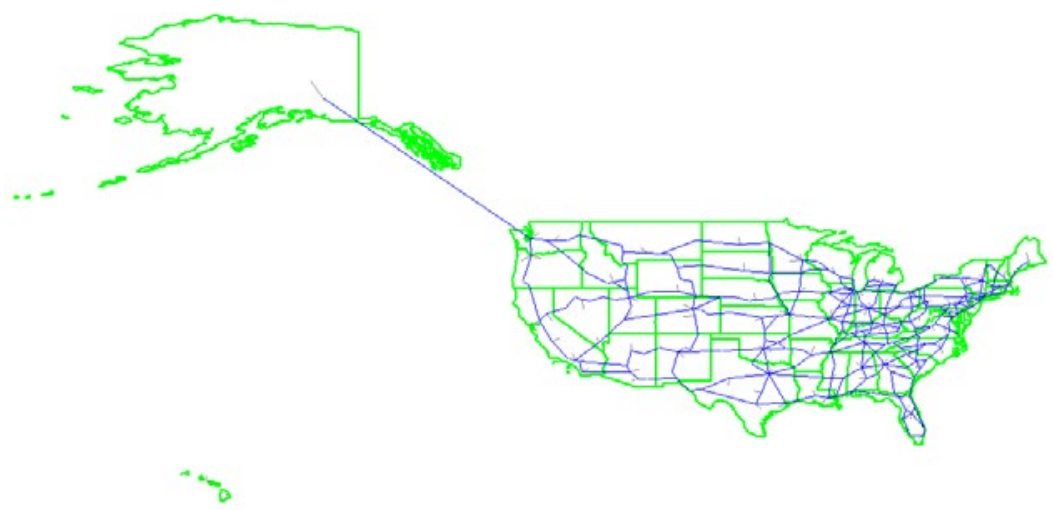

Fig. 2.

National Network in CUBE-TRANPLAN Format 
A variety of CUBE-TRANPLAN modules were used to develop the flow analysis and define the shortest path through the national network between zones. Initially, the network was input to the Highway Selected Summation module to determine the skims, or the shortest path between all 114 zones. Then, the skims were entered into a gravity distribution model, Gravity Model, with a fictitious production and attraction file. The production and attraction file was established with 100,000 productions and attractions for each zone - essentially a large value to ensure some trips would be distributed between each zone pair. Next, a fictitious assignment was performed to utilize the roadway network and place traffic on the roadways utilizing Load Highway Network. The assignment was performed using a shortest path methodology directing all traffic on to the shortest route, regardless of congestion. Finally, the Load Highway Selected Links module was used to extract specific route information.

Using the Load Highway Selected Links module, it was possible to identify selected roadways where only the traffic using the selected roadways would be included in the output. It is possible to identify a collection of links where the travelers have to use all the links identified or only one of the links identified. For Alabama, seven roadways that represented interstates crossing state lines were identified as the selected links. The rule was established that the traffic only needed to use one of the links to be included in the results. In addition, the module allows for the identification of origin locations, destinations locations or a combination of both be identified to limit the amount of traffic stored. In the analysis, as the values external to Alabama were of interest, the origin zones were varied individually from zone 3 - Alaska to zone 114 - Wyoming. Zone 1 and 2 were excluded from the study because they are internal to Alabama.

During the process of running the Load Highway Selected Links for each origin, the output network containing the paths that pass through Alabama were exported to ArcGIS for further analysis. A query was developed to show the destination zones that were on the path through Alabama. The main interest in this step was the development of paths from a single origin to multiple destinations. These values were recorded in a spreadsheet and saved as tab delimited text file. The values, formatted to show the origin zone number, destination A zone number, destination $\mathrm{B}$ zone number, destination $\mathrm{C}$ zone number, etc., were saved for input into the computer program written to extract the FAF2 data.

After developing the origin destination pairs traffic passing through Alabama would use, the next step was to extract the FAF2 data from its native Microsoft Access Database format into a text file. The planner could use the FAF2 data for either 'Kilotons' or 'Millions of Dollar Shipped'. The two text files serve as input to the computer program written to extract the data.

The FAF2 Data Extraction Program creates a text file containing origin, destination and FAF2 value for each commodity listed in the database. In addition, as a parameter input into the program, a search is performed during the operation of the program to extract only data for which "truck" is listed as the mode of transportation. It is important to note, that if the infrastructure were developed for alternative modes, the program could be easily modified to extract rail or water shipment data if the origin

\section{jitte 6}


destination zones were also adjusted to reflect the alternate mode.

The output from the program is a text file that contains origin zone number, destination zone number, and FAF2 data value, either 'Kilotons' or 'Millions of Dollar Shipped', for each commodity in the FAF2 database. Once developed, a TRANPLAN routine was employed to convert the text file into a trip table for entry into CUBE-TRANPLAN. The trip table file is then input to the Load Highway Network module with the national network, to assign the 'Kilotons' or 'Millions of Dollar Shipped’.

The validation of the methodology is difficult because the FAF2 data does not contain vehicle traffic. However, it is possible to perform a limited validation of the methodology. The validation technique involves comparing the tons of freight passing in and out of Alabama to the truck traffic crossing the state line to determine if the values violate truck weight laws, or not.

The assignment by commodity of the external kilotons to the national network is intended to provide a measure of the pass through traffic. However, it is still necessary to collect the internal-external and externalinternal traffic for Alabama since these trips also passes across the state line. The values of kilotons that have either the origin or destination in Alabama are obtained from a direct export from the FAF2 database. The data exported can be sorted and purged such that only those that have their origin or destination in Zone 1 or Zone 2 (Alabama) and sorted by individual commodities to remove all the values that are not moved by "truck". The TRANPLAN routine can be run to create a trip table for entry into the CUBE-TRANPLAN Load Highway Network module.

A collection of the Kilotons crossing the state lines was then compared to the total truck count at the state line interstate locations. The Alabama Department of Transportation (ALDOT) provided the data related to truck counts. Table 1 presents the number of trucks per day reported by ALDOT crossing the Alabama state line. Table 1 also contains the tons of freight per year obtained from the FAF2 database that the methodology suggests crosses the Alabama state line. A comparison of the results indicates that the values obtained by calculating the weight per truck are realistic. The differences in truck weight are associated with the wide variety of commodities shipped via truck across the state lines and the distribution of destinations for those specific commodities.

Table 1

Method Validation

\begin{tabular}{|l|c|c|c|c|c|}
\hline & Trucks/day (7) & Tons/year model & Tons/day & Tons/truck & Pounds/truck \\
\hline I65 & 7,768 & $52,071,250$ & 142,661 & 18.37 & 36,730 \\
\hline I59 & 4,758 & $47,408,170$ & 129,885 & 27.30 & 54,601 \\
\hline I20 & 14,531 & $38,163,040$ & 104,556 & 7.20 & 14,390 \\
\hline I85 & 6,070 & $42,259,400$ & 115,779 & 19.07 & 38,149 \\
\hline I10E & 6,334 & $13,234,480$ & 36,259 & 5.72 & 11,450 \\
\hline I10W & 9,979 & $22,101,760$ & 60,553 & 6.07 & 12,136 \\
\hline I59W & 8,875 & $107,198,800$ & 293,695 & 33.09 & 66,188 \\
\hline
\end{tabular}


The application of the methodology for statewide modeling of pass-through freight is evident thought the use of the forecasted volumes from the FAF2 database. Using the forecasts included with the database and the national networks developed as part of this research, it was possible to obtain a level of pass through freight expected on each major interstate roadway in Alabama for any year in the FAF2 database. Additionally, the volume of pass-through freight can be shown for each year, assuming a value of 16 tons per truck, shown in Table 2. It is important to note at this point that the successive values for increases in pass-through freight are adjusted for the addition of Interstate 22, scheduled to be completed between the 2010 and 2015 forecast.

\section{Table 2}

Volume and Expected Number of Pass-Through Trucks Statewide

\begin{tabular}{|l|l|}
\hline Year & Trucks \\
\hline 2010 & 18,258 \\
\hline 2015 & 20,071 \\
\hline 2020 & 22,485 \\
\hline 2025 & 25,799 \\
\hline 2030 & 30,151 \\
\hline 2035 & 35,554 \\
\hline
\end{tabular}

The number of trucks can be determined for specific MPOs, located on interstate facilities, from this analysis. For example, the Montgomery MPO will have to plan for almost 1,650 trucks passing through the study area between Interstate 85 to Interstate 65 in downtown Montgomery. This is not including the amount of trucks that will be on the interstate associated with trips that originate/terminate within Alabama.

Additionally, the FAF2 data can be used to evaluate the pass-through truck volumes resulting from the port of Mobile on the state and MPOs within the state. Through modeling the port facility separately, it can be seen that there is significant volume of freight moving by truck that is destine for locations outside Alabama and freight is generated outside Alabama destine for the Port of Mobile. Fig. 3 shows an example of this freight.

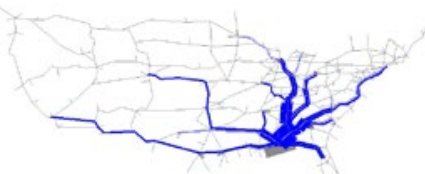

Fig. 3.

Port of Mobile Impact on Pass-Through Freight 2010

Examining the volumes passing-through the Montgomery MPO from the Port of Mobile, in 2010 the number of daily truck passing through Montgomery on Interstate 65 is 168 trucks per day and the number of daily trucks passing through Montgomery using Interstate 85 and Interstate 65 is 118 trucks per day. In 2035, the number of truck per day on Interstate 65 passing through Montgomery increases to 304 and the number of trucks per day on Interstate 85 and Interstate 65 is 190. Again, these trucks need to be accommodated in the planning process, but are not under the control of the local MPO.

The methodology presented in this section of the paper focused on a means to utilize FAF2 data to estimate statewide external traffic levels. The results of using the methodology produce a reasonable value of weight per truck for each interstate route as it crosses the Alabama state line. Additional use of this methodology would be a forecast of 
future years freight tonnage provided in the FAF2 database. Then, the application of a reasonable number of trucks to transport the total tonnage of freight could be ascertained to develop a future freight external flow value.

This methodology has been developed to be applicable to any state, or region identified in the FAF2 zone structure. Future improvements of the methodology would include developing truck weight factors for specific commodities and advancements in disaggregating the FAF2 database to a sub-state level. The method presented here improves the ability of transportation planners to quantify the base level of freight traffic in their area of concern. The base level of freight traffic contributes to total roadway congestion, but is difficult to ascertain because traditional sampling techniques are only available within the study area. The methodology presented in this paper can be used to determine the freight movements that occur simply because the study area is along the travel path between unrelated origins and destinations. Overall, this methodology is intended to serve as a starting point for statewide freight flow models interested in using the FAF2 database, but facing the difficulty in understanding the methods to obtain the data and extract the data that is appropriate.

\section{Local Pass-Through from a Statewide Model}

After looking at the national model for determining the amount of pass-through trucks that would be present simply because Alabama on the shortest path between origin/destination, the next items was to disaggregate the FAF2 to the county level and include the amount of freight traffic that originated/terminated within Alabama. This involved the development of a statewide freight flow model and method to disaggregate the FAF2 data from the two counties provided in the FAF2 database to the 67 counties in Alabama. Then, the modeling environment needed to be adjusted to allow for the freight volumes to be assigned to all possible combinations. Finally, the modeling structure was modified to account for the pass-through that was generated within the state, terminated within the state, or both.

The model that was developed was created in CUBE/TRANPLAN and contains all interstate and US highways in Alabama. Additionally, some state highways were included to provide continuity of the roadway network and make counties accessible. The modeling network developed is shown in Fig. 4.

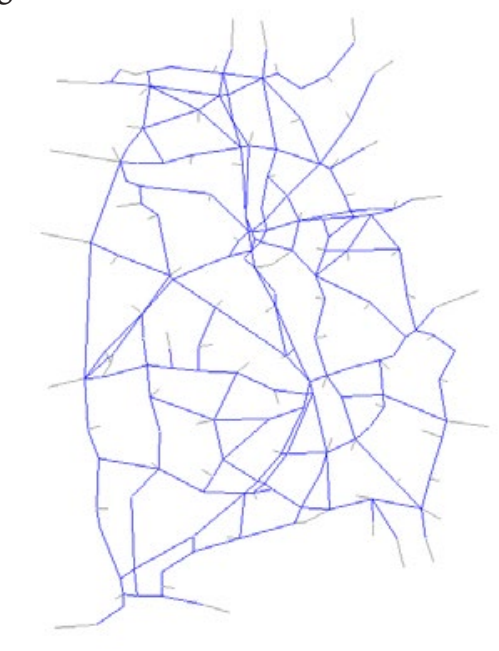

Fig. 4.

Statewide Roadway Network

The model used to disaggregate the FAF2 data to the counties used the personal income 
and value of shipment for the counties. This disaggregation is outlined in the FAF2 report submitted to ALDOT, therefore it not presented here. Additionally, the trip purposes used in the assignment are in the FAF2 report and are not presented here. The modeling effort from the statewide freight model has been validated to 2002 counts obtained from ALDOT. The validation chart is shown in Fig. 5. As evident from the figure, the truck count from the model closely follows the truck count for the roadway. This is evident from the distribution of points lying close to the $1: 1$ slope line.

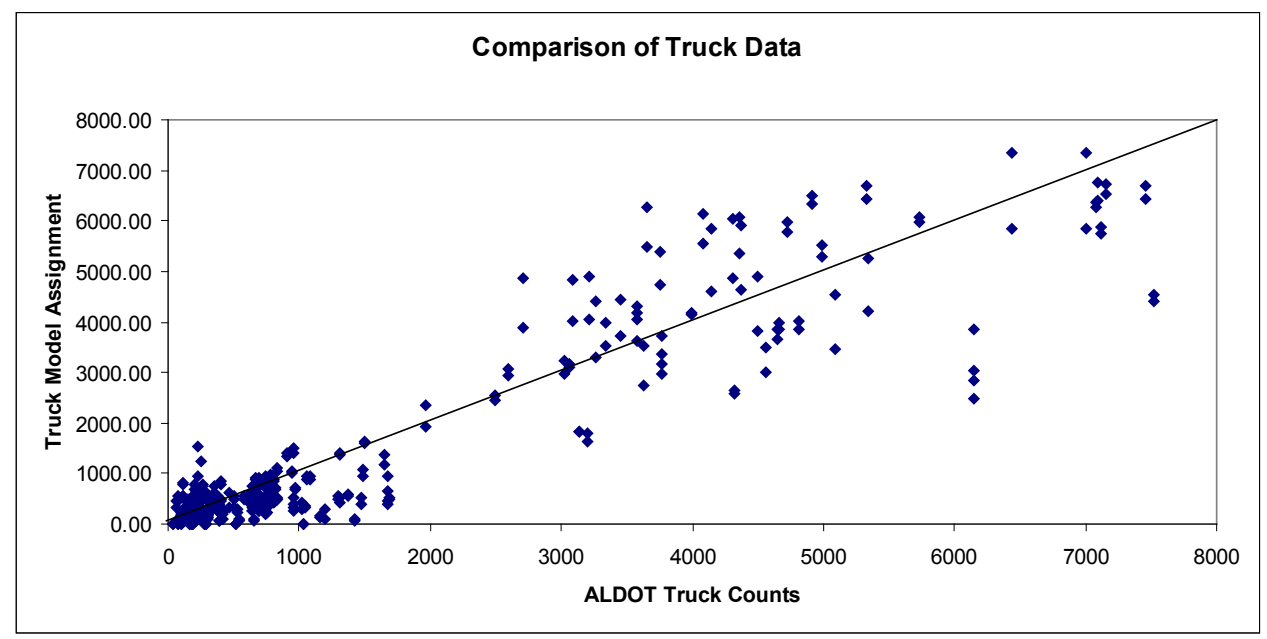

Fig. 5.

Validation of the Statewide Model

The statewide model was also assigned with were used in the process. The 2035 model the FAF2 2035 freight flow data. The same output with roadway thickness proportional disaggregation procedure and trip purposes to daily truck volume is shown in Fig. 6.

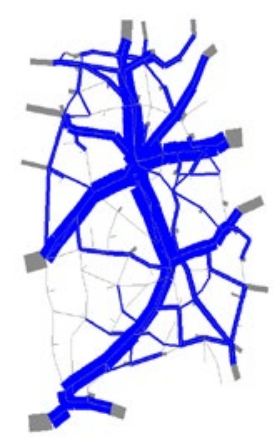

Fig. 6.

Statewide Model with FAF2 2035 Daily Truck Volumes 


\section{Montgomery MPO Case Study}

To demonstrate the applicability of using the FAF2 data for local pass-through modeling, a study was conducted to highlight the truck traffic passing through the Montgomery MPO. For the analysis, the statewide model was used and the CUBE/TRANPLAN control files used to operate the model were adjusted to assign all trips, with the exception of those that originated or terminated within the Montgomery MPO boundary. For the study, the counties that were excluded from the assignment were Montgomery, Autauga and Elmore. It is understood that the Montgomery MPO boundary does not include all of these three counties; however, the majority of activity in these three counties is included in these three counties.

The process of removing the trips from the trip table prior to assigning to the roadway network is performed through a MATRIX UPDATE module in CUBE/TRANPLAN. Additionally, a series of post-processing modules have been developed to identify specific volume of pass-through truck for the MPO. Examining the data for the Montgomery MPO, the pass-through daily truck volumes are shown in Table 3 (note that some truck traffic goes to other roadways).

Table 3

Daily Truck Volumes Expected to Pass-Through Montgomery MPO

\begin{tabular}{|l|l|l|l|}
\hline & \multicolumn{3}{|c|}{ Daily Truck Volumes } \\
\hline Origin Road & $\begin{array}{l}\text { Interstate 65 South of } \\
\text { Montgomery }\end{array}$ & $\begin{array}{l}\text { Interstate 65 North of } \\
\text { Montgomery }\end{array}$ & $\begin{array}{l}\text { Interstate 85 North of } \\
\text { Montgomery }\end{array}$ \\
\hline $\begin{array}{l}\text { Interstate 65 South of } \\
\text { Montgomery }\end{array}$ & $\begin{array}{l}4,900 \text { trucks entering } \\
\text { study area }\end{array}$ & 4,300 trucks & 500 trucks \\
\hline $\begin{array}{l}\text { Interstate 65 North of } \\
\text { Montgomery }\end{array}$ & $\begin{array}{l}4,580 \text { trucks } \\
(140 \text { to West US 80) }\end{array}$ & $\begin{array}{l}6,200 \text { trucks entering } \\
\text { study area }\end{array}$ & $\begin{array}{l}1,540 \text { trucks } \\
(1,290 \text { to South US 231) }\end{array}$ \\
\hline $\begin{array}{l}\text { Interstate 85 North of } \\
\text { Montgomery }\end{array}$ & $\begin{array}{l}1,820 \text { trucks (1,050 to } \\
\text { West US 80) }\end{array}$ & 300 trucks & $\begin{array}{l}2,140 \text { trucks entering } \\
\text { study area }\end{array}$ \\
\hline
\end{tabular}

As can be seen from the table, the daily truck volumes expected to pass-through the Montgomery MPO are significant, especially when considering these identified roadways serve as the main commuter roads for residents of the study area.

\section{Conclusions}

The methodology presented in this paper focuses on a means to utilize FAF2 data to estimate statewide external traffic levels. The results of using the methodology produce a reasonable value of weight per truck for each interstate route as it crosses the Alabama state line. Additional use of this methodology would be a forecast of future years freight tonnage provided in the FAF2 database. Then, the application of a reasonable number of trucks to transport the total tonnage of freight could be ascertained to develop a future freight external flow value.

This methodology has been developed to be applicable to any state, or region identified in the FAF2 zone structure. Future improvements of the methodology would include developing truck weight factors for 
specific commodities and advancements in disaggregating the FAF2 database to a sub-state level. The method presented here improves the ability of transportation planners to quantify the base level of freight traffic in their area of concern. The base level of freight traffic contributes to total roadway congestion, but is difficult to ascertain because traditional sampling techniques are only available within the study area. The methodology presented in this paper can be used to determine the freight movements that occur simply because the study area is along the travel path between unrelated origins and destinations. Overall, this methodology is intended to serve as a starting point for statewide freight flow models interested in using the FAF2 database, but facing the difficulty in understanding the methods to obtain the data and extract the data that is appropriate.

The development of the procedure to forecast pass-through freight within Alabama at the local level involved several steps. Initially, the Freight Analysis Framework, Version 2 Database required study to understand the complexity of the database. Then, the national pass-through freight volumes were researched to understand the implication of freight originating/terminating outside the state and the impact of this freight on roadways within Alabama. Using the statewide model, tools and procedures were developed to examine the impact of Alabama's freight to local areas.

It is important to note that the work presented focuses on Montgomery and the Montgomery MPO. However, this work is transferable to other states and MPOs to provide pass-through freight volumes, which are not readily available and difficult to determine.

\section{Acknowledgements}

This research was sponsored by the Alabama Department of Transportation, "Development of a Method to Forecast Freight Demand Arising from the Final Demand Sector and Examination of Federal Data to Analyze Transportation Demand for Local Area Through Trips, Project 930-697."

\section{References}

ALDOT Traffic Count Maps. Available from Internet: $<$ http://aldotgis.dot.state.al.us/trafficvolume/viewer. htm $>$.

Cohen, H.; Horowitz, A. 2008. Forecasting Statewide Freight Toolkit. NCHRP Report 606. Transportation Research Board of the National Academies. Washington D.C.

FHWA 1. Freight Analysis Framework. Available from Internet: <http://ops.fhwa.dot.gov/freight/freight analysis/faf/index.htm $>$.

FHWA 2. FAF Version 2.2 Available from Internet: <http://www.ops.fhwa.dot.gov/freight/freight analysis/faf/faf2userguide/index.htm $>$.

FHWA 3. Geographic Areas for the Freight Analysis Framework and 2002 Commodity Flow Survey Available from Internet: <http://www.ops.fhwa.dot.gov/freight/ freight_analysis/faf/cfs_faf_areas.htm $>$.

Harris, G.A.; Anderson, M.D. 2008. A Freight Planning Framework, Submitted for presentation at the 2008 Transportation Research Board Annual Meeting and publication in the Journal of the Transportation Research Record.

Horowitz, A. 2006. Statewide Travel Forecasting Models. NCHRP Synthesis 358. Transportation Research Board of the National Academies. Washington D.C. 
Martin, A.; McGuckin, N. 1998. Travel Estimation Techniques for Urban Planning. NCHRP Report 365. Transportation Research Board of the National Research Council. Washington D.C.

Qian, Z.; Han, Y.; Stone, J.R. 2012. Forecasting External Trips in Small and Medium Cities Based on Local Economic Context. In Proceedings of the 8th International Conference on Traffic and Transportation Studies, 284-293.

UAH Office for Economic Development. 2005. Transportation Infrastructure in Alabama-Meeting the Needs for Economic Growth, Final Report on the Requirements for Infrastructure and Transportation to Support the Transformation of the Alabama Economy. Prepared for the Office of the Secretary, U.S. Department of Transportation, Grant No. DTTS59-03-G-00008. 